\title{
Neurological and CT evaluation of knocked-out boxers
}

\author{
IRA R CASSON, RAJ SHAM, EDWIN A CAMPBELL, MILTON TARLAU, \\ ANTHONY DIDOMENICO
}

From the Division of Neurology, Department of Medicine, Queens Hospital Center Affiliation of the Long Island Jewish-Hillside Medical Center, The Computed Tomography Center, Rego Park, New York, the New York State Athletic Commission, The Department of Neurology, State University of New York at Stony Brook and the Department of Neurology, New York University Medical Center

SUMmaRy Detailed neurological examinations, EEG and CT scans of the head were performed on 10 professional boxers aged 20 to 31 years shortly after being knocked-out. Intracerebral and subdural haematomas were not suspected or discovered. However, CT scans revealed cerebral atrophy in five of the boxers; this finding was most common in the boxers with the most bouts. The possible relationship of these findings to the chronic encephalopathy of boxers is discussed.

Six North American professional boxers have died in the past year from injuries sustained in the ring. The Associated Press reports 330 boxing fatalities since $1945 .{ }^{1}$ In response to these deaths, there have been calls to ban boxing or at least institute stricter medical controls to prevent serious injury. Since most boxing deaths are due to acute subdural haematomas and other brain injuries, ${ }^{2}$ we initiated this study of the effects of boxing on the brain. The goals of our study are twofold (1) to determine if CT scanning of the head can contribute to the assessment of boxers' conditions after knockouts and (2) to correlate the results of neurological examination, electroencephalography, and CT scanning in these fighters.

\section{Materials and methods}

Ten active professional boxers who were knocked out in bouts, or were judged by a ringside physician to have sustained significant head trauma in a technical knockout have been included. A "knock-out" occurs when a boxer is knocked to the canvas and is unable to regain erect posture within 10 seconds. Information about the

Address for reprint requests: Ira R Casson, MD, Queens Hospital Center, 82-68 164 Street, Jamaica, New York 11432, USA.

Received 8 April 1981. Accepted 19 October 1981

This study was funded in part by a grant from The Computed Tomography Center, Rego Park, New York. fighter's career and details of his knockouts were obtained from the fighter and confirmed by records at the New York State Athletic Commission. Evaluation of the boxers consisted of (1) a formal neurological examination including a screening mental status examination, (2) an electroencephalogram performed with an 8-channel Hittman Medcraft Mark III electroencephalograph, and (3) a non-contrast CT scan of the head performed with a Picker Synerview 600 fourth generation body scanner. Clinical examination and CT scan were done within one week of the knockout. The EEG was obtained within two weeks of the knockout. Neurological examination, EEG and CT scan were each performed and interpreted independently.

\section{Results}

The boxers' ages ranged from 20 to 31 years. All weight classes have been included, with a preponderance of heavier fighters. The total number of professional bouts per boxer ranged from 2 to 52 . We have included fighters of championship calibre as well as mediocre and poor fighters. All the boxers denied alcoholism or drug use. All the subjects in this study had sustained mild head injuries by clinical criteria. In no case did the duration of loss of consciousness exceed 10 seconds or the duration of post-traumatic amnesia exceed 2 minutes. Nine of the ten boxers had been knocked out. One (No 7) had sustained frequent powerful blows to his head during the two rounds before his fight was stopped due to 
Table Results

\begin{tabular}{|c|c|c|c|c|c|c|c|c|c|}
\hline Boxer & $\begin{array}{l}\text { Age } \\
(y r)\end{array}$ & $\begin{array}{l}\text { Rank, professional } \\
\text { stature }\end{array}$ & $\begin{array}{l}\text { Number of } \\
\text { pro fights }\end{array}$ & $\begin{array}{l}\text { Record } \\
(W-L-T)\end{array}$ & $\begin{array}{l}\text { Times } \\
\text { knocked } \\
\text { out }\end{array}$ & $\begin{array}{l}\text { Duration of loss } \\
\text { of consciousness } \\
\text { in recent } \\
\text { knockout }\end{array}$ & $\begin{array}{l}\text { Mental status } \\
\text { and neurological } \\
\text { examination }\end{array}$ & $C T$ scan & $E E G$ \\
\hline 1 & 25 & Unranked & 22 & $13-7-2$ & 2 & 5 seconds & Normal & $\begin{array}{l}\text { Mild generalised } \\
\text { cerebral atrophy }\end{array}$ & Normal \\
\hline 2 & 20 & Unranked & 2 & $0-2-0$ & 1 & 10 seconds & Normal & Normal & Normal \\
\hline 3 & 31 & $\begin{array}{l}\text { Ranked top } 10 \\
\text { former Olympic } \\
\text { champion }\end{array}$ & 34 & $23-11-0$ & 1 & 5 seconds & Normal & $\begin{array}{l}\text { Moderate central } \\
\text { cerebral atrophy }\end{array}$ & \\
\hline 4 & 23 & Ranked top 10 & 20 & 14-6-0 & 2 & 5 seconds & $\begin{array}{l}\text { Mild organic } \\
\text { mental syndrome; } \\
\text { no focal deficits }\end{array}$ & Normal & Normal \\
\hline 5 & 22 & $\begin{array}{l}\text { USA champion } \\
\text { kickboxer }\end{array}$ & 44 & $43-1-0$ & 1 & 5 seconds & Normal & $\begin{array}{l}\text { Mild generalised } \\
\text { cerebral atrophy }\end{array}$ & Normal \\
\hline 6 & 28 & Unranked & 9 & $6-3-0$ & 1 & $\begin{array}{l}10 \text { seconds (post } \\
\text { traumatic amnesia } \\
2 \text { minutes) }\end{array}$ & Normal & Normal & $\begin{array}{l}\text { Minimally } \\
\text { abnormal } \\
\text { anteriorly more } \\
\text { on left }\end{array}$ \\
\hline 8 & 21 & Unranked & 4 & $2-2-0$ & 2 & 2 seconds & Normal & $\begin{array}{l}\text { Mild generalised } \\
\text { cerebral atrophy }\end{array}$ & Normal \\
\hline 9 & 28 & Unranked & 12 & $8-4-0$ & 1 & 1 second & Normal & Normal & Normal \\
\hline 10 & 23 & Unranked & 9 & $6-3-0$ & 2 & 10 seconds & Normal & Normal & Normal \\
\hline
\end{tabular}

his profuse facial bleeding. All the boxers were fully alert and oriented at ringside examination after the fight.

The details of each subject's boxing career and the results of his clinical examination, EEG and CT scan are depicted in the table. Only one boxer (No 4) had an abnormal neurological examination; he had a mild organic mental syndrome manifested by impairment of recent memory and recall, confusion and dyscalculia. There were no focal neurologic deficits. The EEG and CT scan were normal.

Five boxers had definitely abnormal CT scans, three with mild generalised cerebral atrophy and two with central cerebral atrophy. One of these boxers also had a cavum septum pellucidum (fig 1). A generalised atrophy pattern is one in which there is cortical sulcal prominence and commensurate dilatation of the ventricular system (figs 3, 4). The central atrophy pattern consists of dilatation of the ventricular system without evidence of an obstructive lesion and with little or no cortical sulcal prominence (figs 1, 2). No extracerebral or intracerebral haematomas, contusions, oedema, white matter demyelination, infarcts or areas of porencephaly were identified.

Two boxers had abnormal EEGs, both with increased slowing in the theta range anteriorly, bilaterally but asymmetrically. Both had normal
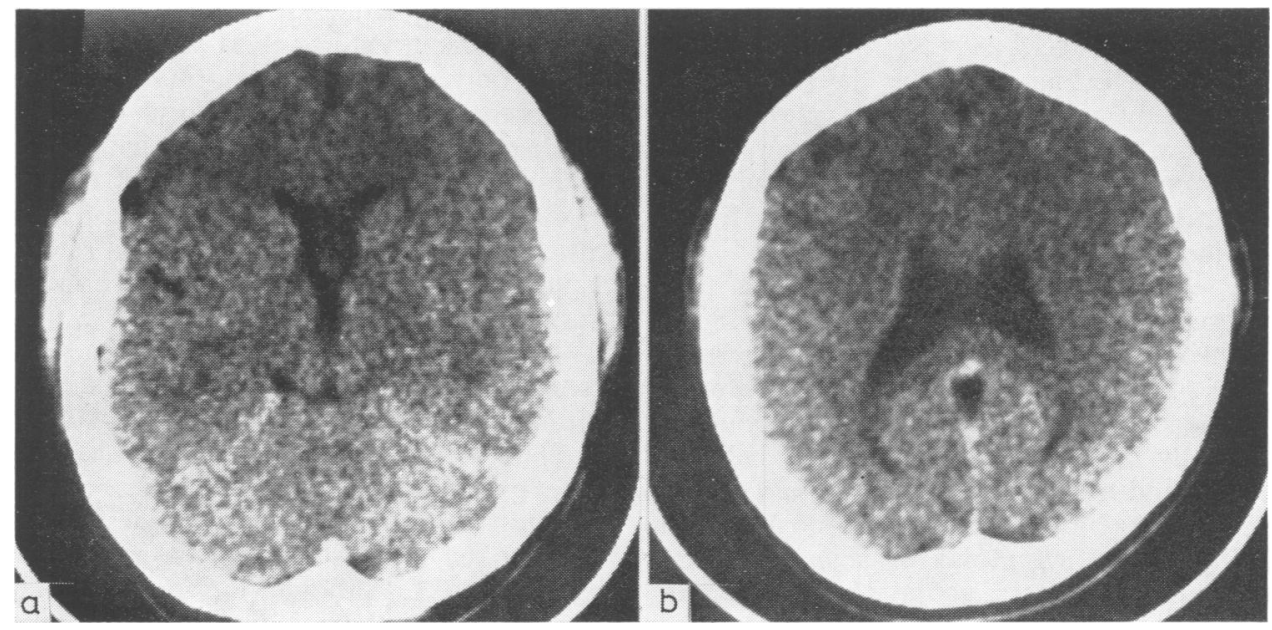

Fig 1 Boxer 7. CT scan of the head demonstrating a cavum septum pellucidum (a) and mild dilatation of the third (a) and lateral ventricles (b). 

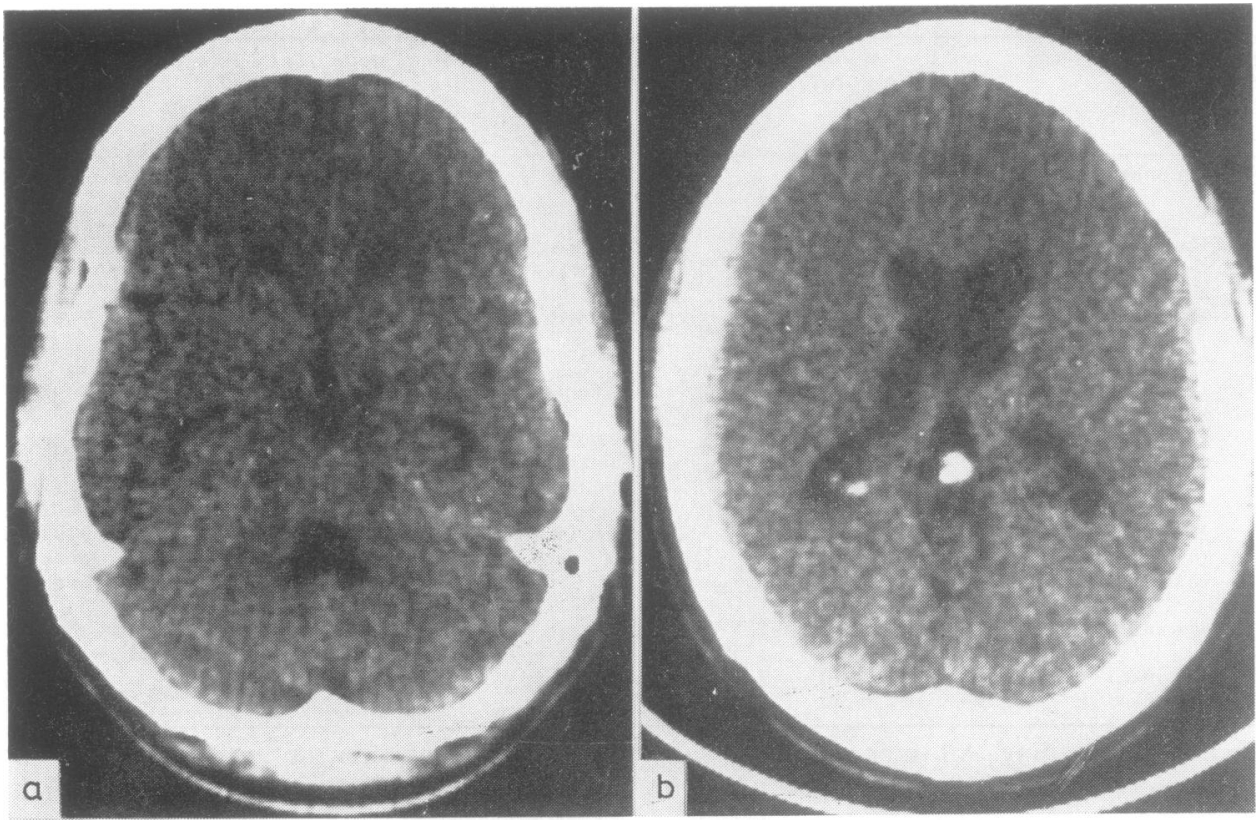

Fig 2 Boxer 3. CT scan of the head demonstrating moderate ventricular dilatation (b) including the temporal horns and the fourth ventricle (a).

clinical examinations. One had a normal CT scan; the other had a central atrophy pattern and a cavum septum pellucidum on CT scan.

\section{Discussion}

Boxing is a violent sport in which the participants intentionally attempt to knock out their opponent. Although it has been claimed that very few effective head blows are delivered in professional fights, ${ }^{3}$ the alarming incidence of serious head injuries in boxers provides clearcut evidence of the dangers of the sport. This study was initiated to determine if neurological evaluation, electroencephalography and computed tomography might uncover some unsuspected brain injury or help to prevent some future cerebral injury.

Routine electroencephalography of active professional boxers shortly after bouts has previously been reported three times, with inconclusive results. Two studies of small groups of boxers demonstrated a high incidence of abnormal EEGs after bouts. ${ }^{45}$ Another study revealed no differences between EEGs before and after fights in $\mathbf{4 0}$ boxers. ${ }^{3}$ To date, CT scanning of the head has been performed only on boxers with clinical symptoms or signs of severe head injury. In these cases, acute subdural haematomas, intracerebral haemorrhages and contusions have been discovered. ${ }^{6}$ CT scan of the head without contrast performed within one week of civilian acute closed head injury is an extremely sensitive test for the diagnosis of intra-axial or extra-axial haemorrhages, contusions and oedema. ${ }^{7}$ This is the first study in which a consecutive series of professional boxers had CT scans of the head shortly after routine knockouts.

All the boxers had mild head injuries by clinical criteria, with duration of loss of consciousness and post-traumatic amnesia of less than 2 minutes. Civilian patients with cerebral concussions by clinical criteria only rarely have abnormal CT scans. Thus, the absence of epidural, subdural or intracerebral haemorrhages, contusions, subarachnoid bleeding, oedema or evidence of white matter demyelination on CT scans in these boxers was not unexpected. Little or no correlation between neurological evaluation, EEG and CT scan also should come as no surprise to clinicians.

We were surprised by the finding of cerebral atrophy on the CT scans of half these active boxers. Within our group, the age of the fighters did not correlate with the presence of cerebral atrophy. The more proficient fighters more often had cerebral atrophy than the less proficient ones. Three of the four ranked boxers in this series had cerebral atrophy on CT. Although the fourth had a normal CT scan, he was the only boxer in the series with an organic mental syndrome. All three of the fighters 

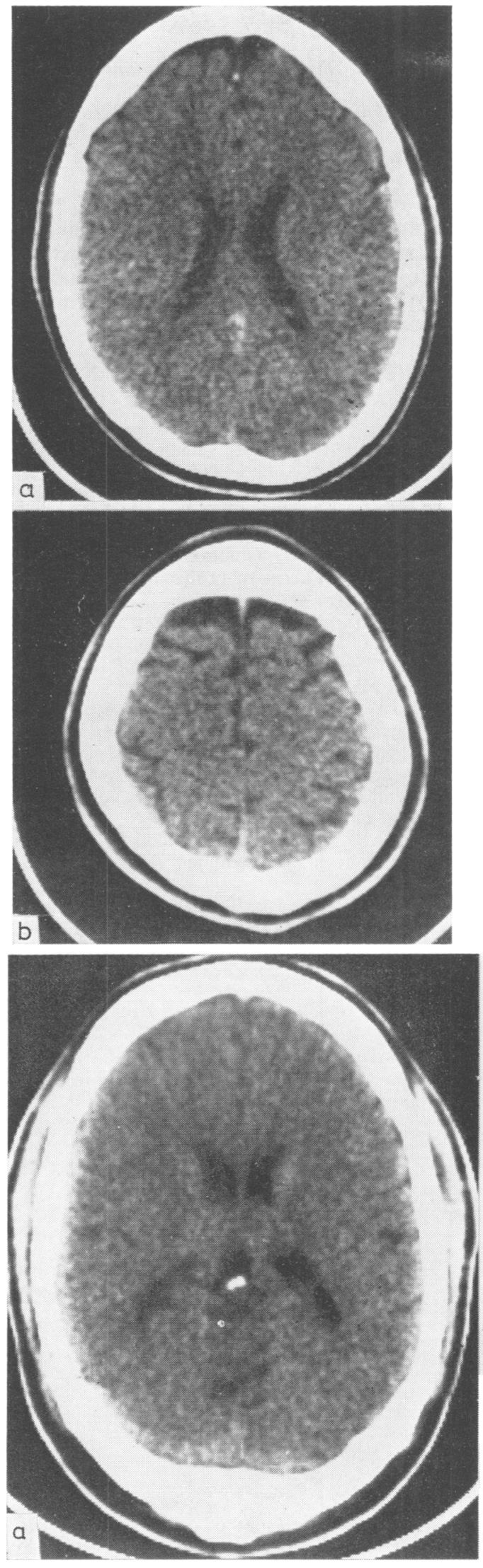

Fig 3 Boxer 5. CT scan of the head demonstrating mild ventricular dilatation (a) and mild to moderate cortical atrophy (b).

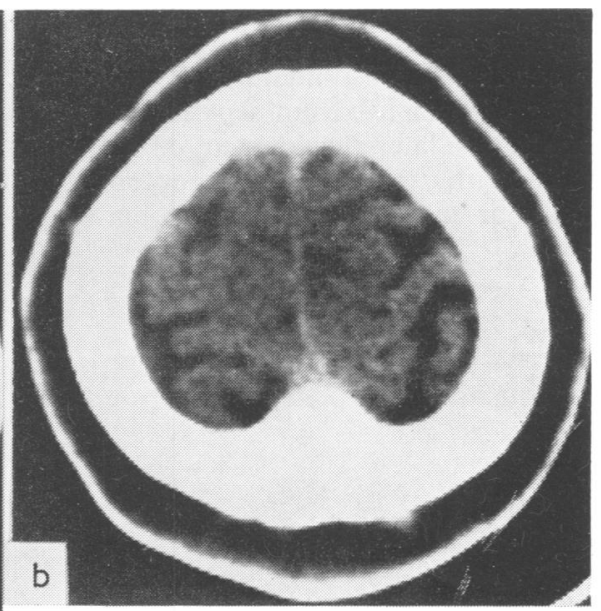

Fig 4 Boxer 1. CT scan of the head demonstrating mild ventricular dilatation (a) and mild to moderate cortical atrophy (b). 
who had attained champion status during their careers had cerebral atrophy on CT scan and no organic mental syndrome. The total number of professional bouts entered also correlated with the CT abnormalities. Of the five fighters with 20 or more fights, four had cerebral atrophy; of the five fighters with under 12 fights, only one had cerebral atrophy. The number of fights, not the proficiency of the boxer, may be the critical factor. Since none of the boxers had been knocked out more than two times in their careers, a cumulative effect of multiple subconcussive head blows is the most likely culprit.

This preliminary investigation suggests that these CT abnormalities are related to the chronic encephalopathy of boxers. Since Martland's original description, ${ }^{9}$ the "punch-drunk" syndrome of cerebellar ataxia, Parkinsonian features and dementia has frequently been described in former professional boxers. Roberts found that the severity of the syndrome was highly correlated with the length of a boxer's career and the total number of bouts fought. ${ }^{10}$ In cases of chronic boxers' encephalopathy in which pneumoencephalography was performed, diffuse cerebral atrophy and cavum septum pellucidum were often noted. ${ }^{11}$ A specific neuropathological pattern of brain damage in former boxers consisting of abnormalities of the septum pellucidum (tears, perforations, cavum septum), focal scarring of cerebral and cerebellar hemispheres, ventricular dilatation with minimal cortical atrophy, degeneration of the substantia nigra and widespread neurofibrillary tangles has been described. ${ }^{12}{ }^{13}$ One of our boxers (No 7) had a cavum septum pellucidum with central cerebral atrophy on CT scan. This former world champion's style of fighting has always been that of a "slugger" and he is noted for the great deal of battering punishment that he has received as well as given. We submit that CT findings of cerebral atrophy, with or without a cavum septum pellucidum, might predict the later development of clinical chronic encephalopathy in presently asymptomatic active boxers. If our continuing study corroborates this reputed link, perhaps certain boxers can be advised to retire from the ring before irreversible damage has occurred.

The authors thank Morton Nathanson, MD for reviewing the manuscript, Mrs Cathryn Einhorn and Ms Sandy Margulies for their invaluable assistance, Ms Miriam Regenworm for typing the manuscript and $\mathrm{Mr}$ Martin Rosenberg for performing the electroencephalograms.

\section{References}

${ }^{1}$ Rogers T. Canadian boxer dies after fight injury. The New York Times 1980;July 8:B10.

${ }^{2}$ Critchley M. Medical aspects of boxing, particularly from a neurological standpoint. Br Med J 1957;1: 357-62.

${ }^{3}$ Kaplan H, Browder J. Observations on the clinical and brain wave patterns of professional boxers. JAMA 1954;156:1138-44.

${ }^{4}$ Larsson LE, Melin KA, Nordstrom-Ohrberg G, Silverskiold BP, Ohrberg K. Acute head injuries in boxers. Acta Psychiatrica Neurol Scand 1954; Suppl. 95:1-42.

${ }^{5}$ Busse EW, Silverman AJ. Electroencephalographic changes in professional boxers. JAMA 1952;149: 1522-5.

${ }^{6}$ Cruikshank JK, Higgens CS, Gray JR. Two cases of acute intracranial hemorrhage in young amateur boxers. Lancet 1980;1:626-7.

${ }^{7}$ Dublin AB, French BN, Rennick JM. Computed tomography in head trauma. Radiology 1977;122: 365-9.

${ }^{8}$ Koo AH, LaRoque RL. Evaluation of head trauma by computed tomography. Radiology 1977;123:345-50.

${ }^{9}$ Martland HS. Punch drunk. JAMA 1928;91:1103-7.

${ }^{10}$ Roberts AH. Brain damage in boxers. London: Pitman, 1969.

${ }^{11}$ Spillane JD. Five boxers. Br Med J 1962;2:1205-10.

12 Payne EE. Brains of boxers. Neurochirurgia 1968;11: 173-88.

${ }^{13}$ Corsellis JAN, Bruton CJ, Freeman-Browne D. The aftermath of boxing. Psychol Med 1973;3:270-303. 